\title{
Shifts in Thioredoxin Reductase Activity and Oxidant Status in Mononuclear Cells Obtained from Transition Dairy Cattle
}

\author{
L. M. Sordillo, ${ }^{1}$ N. O'Boyle, J. C. Gandy, C. M. Corl, and E. Hamilton \\ Large Animal Clinical Sciences, College of Veterinary Medicine, Michigan State University, East Lansing 48824
}

\begin{abstract}
Measures of oxidative status were examined in 14 dairy cows during the transition period. Blood samples were obtained approximately $21 \mathrm{~d}$ before expected calving, at calving, and again at $21 \mathrm{~d}$ in milk (DIM). Plasma samples were used to determine lipid hydroperoxide concentrations. Total white blood cells were used to determine the oxidative status of glutathione. Peripheral blood mononuclear cell (PBMC) lysates were used to determine the total antioxidant potential and enzymatic activities of glutathione peroxidase (GPX) and thioredoxin reductase (TrxR1). Both plasma lipid hydroperoxide concentrations and GPX activity in PBMC increased at calving and during the first 21 DIM when compared with prepartum samples. Conversely, the total antioxidant potential and TrxR activity declined in PBMC during the first 21 DIM, even though both GPX activity and the glutathione-to-GSSG ratio remained elevated during this time period. Results from this study support previous findings that report increased GPX activity when reactive oxygen metabolites, including lipid hydroperoxides, increase in transition dairy cows. The significant decrease in TrxR activity with a concomitant decrease in total antioxidant potential in PBMC during this same stage of lactation, however, would suggest that this selenoprotein is not able to rebound during periods of oxidative stress to the same extent as GPX1. This study shows for the first time that TrxR may be an important antioxidant defense mechanism in PBMC that is compromised during the periparturient period.
\end{abstract}

Key words: oxidative stress, antioxidant, thioredoxin reductase, selenium

\section{INTRODUCTION}

Dairy cattle are more susceptible to a variety of metabolic and infectious diseases during the transition period compared with peak or late lactation. A large inci-

Received May 1, 2006.

Accepted October 10, 2006.

${ }^{1}$ Corresponding author: sordillo@msu.edu dence of disease in periparturient cows has been ascribed in part to diminished immune cell functions (Sordillo, 2005). Host defense mechanisms can be compromised directly because of numerous physiological and environmental factors during the transition period. For example, physiological stresses associated with rapid differentiation of secretory parenchyma, intense mammary gland growth, and the onset of copious milk synthesis and secretion are accompanied by a high energy demand and an increased oxygen requirement (Gitto et al., 2002). This increased oxygen demand augments the production of oxygen-derived reactants, collectively termed reactive oxygen species (ROS). When overproduced, ROS are important mediators of cell and tissue injury and can lead to a condition referred to as oxidant stress. Host tissues have several enzymes and small molecules that can reduce ROS to less reactive metabolites, and it is this antioxidant capability that helps to protect cells from the damaging effects of oxidant stress. Therefore, an imbalance between increased production of ROS and reduced availability of antioxidant defenses near the time of parturition increases oxidative stress and may contribute to periparturient disorders in dairy cows (Miller et al., 1993; Waller, 2000; Gitto et al., 2002).

The ability to control the degree of oxidative stress can be effective in ameliorating the severity of diseases in transition cows. This was best illustrated by earlier studies (Smith et al., 1984; Erskine et al., 1987, 1989) showing that dairy cattle with existing deficiencies in Se had more severe clinical symptoms of coliform mastitis when compared with cows supplemented with adequate concentrations of this micronutrient. Although supplementing dairy cattle with Se is a widely accepted management practice to avoid deficiencies, it is important to note that the underlying mechanisms for the benefits of Se are not completely known. Since the discovery of selenocysteine (SeCys) as the 21st AA in proteins, the field of Se biology has expanded rapidly. Indeed, many of the beneficial effects of this micronutrient are now known to be mediated by selenoproteins, which have SeCys residues incorporated into their active sites and have important antioxidant enzymatic functions (Schomburg et al., 2004). Glutathione peroxi- 
dase (GPX) has been the selenoprotein most often associated with Se nutritional status, antioxidant capabilities, and neutrophil function in dairy cattle (Grasso et al., 1990; Wichtel, 1998; Weiss and Hogan, 2005). Previous studies showed that GPX plays an important role in reducing harmful ROS and can act in concert with vitamin $\mathrm{E}$ to prevent peroxidation of membrane lipids. Determination of cellular or plasma GPX activity is often used as a diagnostic tool when assessing the Se status of dairy cows because both increase proportionately with Se supplementation up to a certain limit. It is now recognized, however, that many other bovine antioxidant selenoproteins exist, including selenoprotein P, 5 different isoforms of Se-dependent GPX, and 3 thioredoxin reductase (TrxR) isoenzymes (Hara, 2001; Grignard et al., 2005). Recent studies have shown that bovine cytosolic TrxR is a potent antioxidant that can not only reduce harmful ROS directly, but also facilitate the gene expression of other cytoprotective antioxidant factors (Nakamura, 2005; Trigona et al., 2006). However, the potential role of TrxR activity relative to the antioxidant capabilities of dairy cattle immune cell populations has not been documented to date. The present study investigated the relationship of both GPX and TrxR activities with other measures of oxidative status in peripheral blood mononuclear cells (PBMC) obtained from periparturient dairy cows.

\section{MATERIALS AND METHODS}

\section{Cows and Sample Collection}

Fourteen pluriparous Holstein cows at approximately $21 \mathrm{~d}$ before anticipated calving were selected from a commercial herd of 3,000 dairy cows. All cows were supplemented with an injection of Se (Mu-Se Injection; Schering-Plough Cow Health, Kenilworth, NJ) at approximately $1 \mathrm{~mL} / 100 \mathrm{~kg}$ of BW at approximately $3 \mathrm{wk}$ before calving. The cows were monitored for health status throughout the trial and exhibited no lameness or other disease. Following calving and throughout the first 21 DIM, the experimental cows were free of IMI, as indicated by negative bacteriological quarter milk samples and milk SCC $<250,000$ cells $/ \mathrm{mL}$. The diet administered during the trial consisted of a base ration given ad libitum as a TMR. Chemical analyses of the TMR showed that the $\mathrm{CP}$ content was $17.14 \%, \mathrm{NE}_{\mathrm{L}}$ was $1.88 \mathrm{Mcal} / \mathrm{kg}$, and $\mathrm{NDF}$ was $31.90 \%$. A detailed description of the diet composition is given in Table 1.

Blood samples were obtained by jugular venipuncture at approximately $21 \mathrm{~d}$ before calving $( \pm 7 \mathrm{~d})$, at calving $( \pm 3 \mathrm{~d})$, and again at 21 DIM. The prepartum samples were obtained immediately before cows received the supplemental Se injection. Samples were collected with EDTA as the anticoagulant and were
Table 1. Ingredient and nutrient composition of the experimental animal diet (\% of DM)

\begin{tabular}{|c|c|c|}
\hline Item & $\begin{array}{l}\text { Prefresh } \\
\text { period }\end{array}$ & $\begin{array}{c}\text { Lactation } \\
\text { period }\end{array}$ \\
\hline \multicolumn{3}{|l|}{ Ingredient } \\
\hline Corn silage & 46.45 & 29.59 \\
\hline Wheat straw & 16.08 & 1.85 \\
\hline Alfalfa haylage & 18.76 & 11.14 \\
\hline Canola meal & 0.00 & 4.25 \\
\hline Bakery by-product & 7.15 & 10.36 \\
\hline Beet pulp & 0.00 & 3.70 \\
\hline Cottonseed & 0.00 & 6.94 \\
\hline Distillers grains (corn) & 0.00 & 6.45 \\
\hline Ground corn & 0.00 & 12.70 \\
\hline Soybean meal & 5.36 & 9.25 \\
\hline Vitamin-mineral supplement ${ }^{1}$ & 6.20 & 3.77 \\
\hline \multicolumn{3}{|l|}{ Nutrient composition, DM basis } \\
\hline $\mathrm{NE}_{\mathrm{L}}, \mathrm{Mcal} / \mathrm{kg}$ & 1.51 & 1.88 \\
\hline $\mathrm{CP}, \%$ & 14.24 & 17.14 \\
\hline $\mathrm{NDF}, \%$ & 46.60 & 31.90 \\
\hline
\end{tabular}

${ }^{1}$ Containing $109 \mathrm{~g}$ of $\mathrm{Ca}, 93 \mathrm{~g}$ of $\mathrm{P}, 51 \mathrm{~g}$ of $\mathrm{Mg}, 283 \mathrm{~g}$ of $\mathrm{K}, 54 \mathrm{~g}$ of $\mathrm{S}, 124 \mathrm{~g}$ of Na, $144 \mathrm{~g}$ of Cl, 4,827 $\mathrm{mg}$ of $\mathrm{Zn}, 636 \mathrm{mg}$ of Cu, $1,777 \mathrm{mg}$ of Mn, $12.3 \mathrm{mg}$ of Se, $174 \mathrm{kIU}$ of vitamin A, $43 \mathrm{kIU}$ of vitamin D, and $1,077 \mathrm{kIU}$ of vitamin $\mathrm{E}$.

processed within $2 \mathrm{~h}$ of plasma collection and $\mathrm{PBMC}$ isolation.

\section{Lipid Hydroperoxide Assay}

The total lipid hydroperoxides present in plasma samples were measured by detecting redox reactions with ferrous ions by using a Lipid Hydroperoxide Assay Kit (Cayman Chemical, Ann Arbor, MI). Briefly, lipid hydroperoxides were extracted from the plasma samples by using a modified version of an established method (Bligh and Dyer, 1959), along with a deproteination step to eliminate interference from hydrogen peroxide or endogenous ferric ions in the samples. The assay was continued by combining $5 \mu \mathrm{L}$ of extracted sample or standard, $245 \mu \mathrm{L}$ of chloroform, $225 \mu \mathrm{L}$ of chloroform:methanol (2:1), and $25 \mu \mathrm{L}$ of chromogen. Samples and standards ( 0 to $5 \mathrm{nmol}$ of lipid hydroperoxides) were included in triplicate, adding $150 \mu \mathrm{L}$ per well in a glass 96-well microplate. Absorbance was read at $500 \mathrm{~nm}$ using a Wallac Victor3 1420 Multilabel Counter (Perkin-Elmer, Wellesley, MA). The nanomoles of lipid hydroperoxides in each sample were calculated by using a standard curve.

\section{Antioxidant Potential of PBMC}

The antioxidant potential of isolated PBMC was determined using the Bioxytech AOP-490 assay kit (Oxis Research, Portland, OR), which measures the ability of all available antioxidants to reduce copper. Blood cells were separated from plasma by centrifugation, sus- 
pended in buffer, and layered onto Ficoll-Paque (Amersham Biosciences, Uppsala, Sweden) with a specific density of $1.077 \mathrm{~g} / \mathrm{mL}$. After centrifugation at $400 \times \mathrm{g}$ for 30 min, PBMC were recovered from the plasma-Ficoll interface and washed in buffer, and viable cell numbers were determined by trypan blue dye exclusion. Isolated PBMC were washed 3 times in ice-cold PBS before sonication. The PBMC homogenates were centrifuged at $3,000 \times g$ for $15 \mathrm{~min}$ at $4^{\circ} \mathrm{C}$, after which supernatants were collected and stored at $-80^{\circ} \mathrm{C}$. Protein concentrations were measured with the Coomassie Plus Protein Assay Reagent (Pierce, Rockford, IL) according to the manufacturer's instructions. Uric acid standards were prepared, ranging from 2.0 to $0.03125 \mathrm{mM}$. Briefly, 2.5 $\mu \mathrm{L}$ of standard or $10 \mu \mathrm{L}$ of sample was diluted in assay buffer containing bathocuproine to a final volume of $100 \mu \mathrm{L}$ and were then added to a 96-well microplate in duplicate. A reference measurement was taken at 490 $\mathrm{nm}$ using the Wallac Victor3 1420 Multilabel Counter followed by the addition of $25 \mu \mathrm{L}$ of assay buffer containing $\mathrm{Cu}^{2+}$ for 3 min of incubation at room temperature. Finally, $25 \mu \mathrm{L}$ of stop solution was added, mixed, and the plate was read again at $490 \mathrm{~nm}$. Following subtraction of the reference measurement from the final measurement, the standard curve was used to calculate the copper reducing equivalents per microgram of protein.

\section{Glutathione Measures in Whole Blood}

The amount of reduced glutathione (GSH) to oxidized glutathione (GSSG) was measured using the Bioxytech GSH/GSSG-412 Kit (Oxis Research). The GSH-toGSSG ratio was calculated from the following equation: (GSH - 2GSSG)/GSSG.

Whole blood was aliquoted from EDTA collection tubes within $2 \mathrm{~h}$ of collection and a thiol scavenger (M2VP) was immediately added to the GSSG samples before freezing at $-80^{\circ} \mathrm{C}$. The GSH-to-GSSG ratio was determined in the presence of 5-5'-dithiobis(2-nitrobenzoic acid) and NADPH according to the supplied manufacturer's protocol. Briefly, the change in absorbance at $412 \mathrm{~nm}$ over $3 \mathrm{~min}$ was measured using a spectrophotometer for both samples and standards (0 to $1.5 \mathrm{mM}$ of GSSG). The GSH-to-GSSG ratio was calculated using a standard curve and the sample reaction rates.

\section{GPX Activity}

Whole cell lysates were harvested from PBMC using M-PER reagent (Pierce) according to the manufacturer's protocol. The GPX activity of PBMC lysates was determined as described previously (Sordillo et al., 1998) using a coupled-enzymatic assay in which oxida- tion of NADPH was monitored spectrophotometrically, whereas peroxidase activity was determined using $\mathrm{H}_{2} \mathrm{O}_{2}$ as a substrate. Data were standardized per milligram of total protein in the whole cell lysates. One unit of activity was defined as the amount of enzyme oxidizing one micromole of NADPH/min.

\section{TrxR Activity}

The TrxR activity was determined in lysates of PBMC by using the standard insulin-based method developed previously (Holmgren and Björnstedt, 1995). Briefly, each assay cuvette contained $40 \mu \mathrm{L}$ of a reaction mixture consisting of $0.26 M$ HEPES, $10 \mathrm{~m} M$ EDTA, 6.4 $\mu \mathrm{g} / \mu \mathrm{L}$ of insulin, and $2 \mu \mathrm{g} / \mu \mathrm{L}$ of NADPH. Each sample was run in the absence and presence of $5 \mu M$ Escherichia coli thioredoxin (Sigma, St. Louis, MO). The reaction was started by the addition of $30 \mu \mathrm{L}$ of PBMC lysate (30 to $50 \mu \mathrm{g}$ of protein) and brought up to a final volume of $120 \mu \mathrm{L}$ with water. Following a 20-min incubation period at $37^{\circ} \mathrm{C}$, the reaction was stopped with $500 \mu \mathrm{L}$ of $0.4 \mathrm{mg} / \mathrm{mL} 5$-5'-dithiobis(2-nitrobenzoic acid)/6 $M$ guanidine hydrochloride in $0.2 M$ Tris- $\mathrm{HCl}$, $\mathrm{pH}$ 8.0. The absorbance was read at $412 \mathrm{~nm}$. The reaction without thioredoxin was subtracted from the thioredoxin-dependent reaction, and TrxR activity was expressed as $\mathrm{A}_{412}$ units $\times 1,000 /(\mathrm{min} \cdot \mathrm{mg}$ of protein) (Hill et al., 1997).

\section{Statistical Analysis}

All variables used to assess oxidative status were analyzed as repeated measures using a mixed model procedure (PROC MIXED; SAS Inst. Inc., Cary NC). The following model was used to estimate the sampling day effect on each of the measured variables:

$$
\mathrm{Y}_{\mathrm{ij}}=\mu+\mathrm{W}_{\mathrm{i}}+\mathrm{e}_{\mathrm{ij}},
$$

where $Y_{i j}$ is the dependent variable for cow ${ }_{i}$ in week $k_{j}$ relative to calving; $\mu$ is the overall mean of the population; $\mathrm{W}_{\mathrm{j}}$ is the fixed effect of week relative to calving, with week as the repeated factor; and $\mathrm{e}_{\mathrm{ij}}$ is the random error, assumed to be correlated. Data are presented as least squares means \pm standard error of the least squares means. Means were separated by the TukeyKramer option in SAS. The CORR procedure of SAS with the Spearman option was used to determine correlations between selenoprotein activity and antioxidant potential within weeks relative to calving. The MIXED procedure of SAS with the Tukey-Kramer option was used to determine correlations between selenoprotein activity and antioxidant potential across weeks relative to calving. 


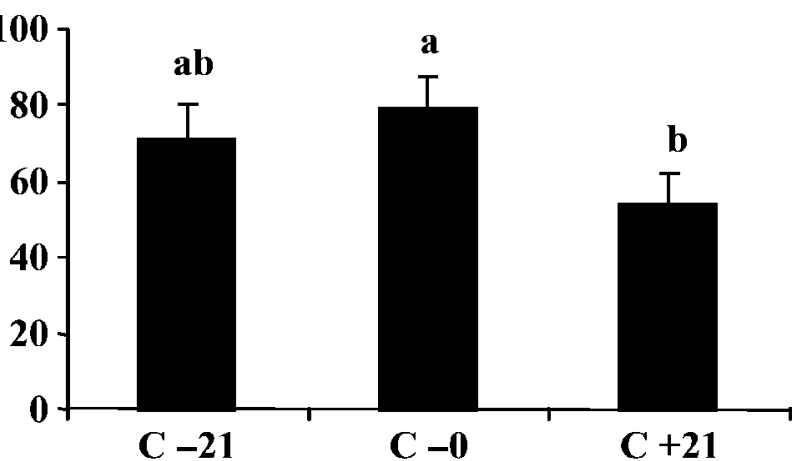

Figure 1. Changes in the total antioxidant potential of white blood cells obtained approximately $21 \mathrm{~d}$ before calving $(\mathrm{C}-21)$, at calving $(\mathrm{C}-0)$, and $21 \mathrm{~d}$ after calving $(\mathrm{C}+21)$. Data are expressed as least squares means $\pm \mathrm{SE} .{ }^{\mathrm{a}, \mathrm{b}}$ Bars bearing different letters differ $(P<0.05)$.

\section{RESULTS AND DISCUSSION}

Free radicals are produced continuously during aerobic metabolism, and concentrations may increase dramatically during increased production demands or as a result of certain pathological conditions (Miller et al., 1993; Matés and Sánchez-Jiménez, 1999). Although molecular oxygen is required for normal cellular functions in mammals, excess accumulation of ROS can cause cell and tissue injury and lead to a condition referred to as oxidative stress. The antioxidant capability of the host can help to protect cells from the damaging effects of excess ROS. These antioxidants can be found as water-soluble or lipid-soluble molecules that are localized transiently throughout tissues and various cell types (Matés and Sánchez-Jiménez, 1999). Given the multiplicity of antioxidant pathways, their centrality in the prevention of oxidative stress, and the influences of diet on overall antioxidant capacity, it is important to be able to measure the total antioxidant capacity or antioxidant power quantitatively within biological specimens. In our study, the assay used to determine the total antioxidant potential of PBMC obtained from transition cows was based on the reduction of $\mathrm{Cu}^{2+}$ to $\mathrm{Cu}^{+}$by the combined action of all antioxidants present in the sample. The antioxidant potential of isolated PBMC remained relatively constant from $3 \mathrm{wk}$ before calving and through calving, but decreased $(P<$ 0.05 ) by 21 DIM (Figure 1). These findings are consistent with reports in both humans and dairy cattle that showed a relationship between the physiological changes during late pregnancy and parturition, with a loss in overall antioxidant potential in several different tissue compartments (Gitto et al., 2002; Bernabucci et al., 2005; Castillo et al., 2005). Lower antioxidant potential as a consequence of lactation stage can result from

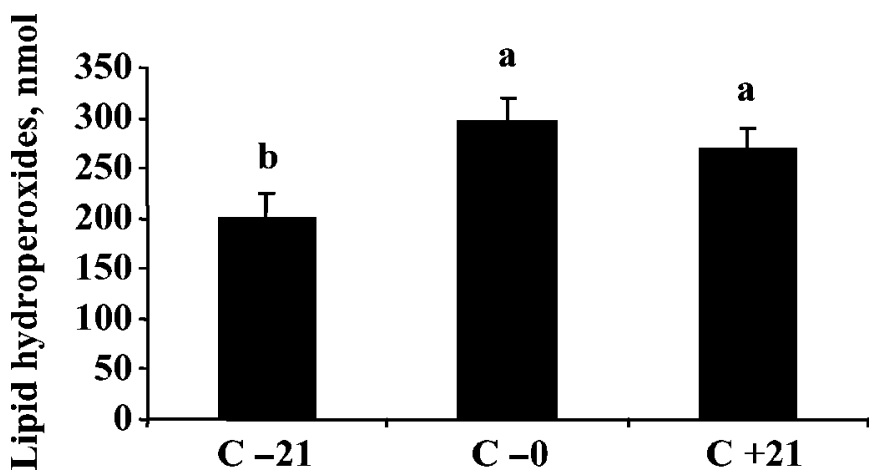

Figure 2. Changes in lipid hydroperoxide levels in plasma samples obtained approximately $21 \mathrm{~d}$ before calving $(\mathrm{C}-21)$, at calving $(\mathrm{C}-0)$, and $21 \mathrm{~d}$ after calving $(\mathrm{C}+21)$. Data are expressed as least squares means \pm SE. ${ }^{a, b}$ Bars bearing different letters differ $(P<0.05)$.

an excess accumulation of ROS, a depletion of antioxidant defenses, or both. Although the individual antioxidant pathways that are compromised cannot be identified with this particular assay, it is clear that earlylactating cows are more sensitive to oxidative stress than are cows in the prepartum period.

High concentrations of ROS can compromise cellular function by damaging DNA and RNA and by altering proteins, carbohydrates, and lipids within cellular membranes. One way to determine whether ROS-mediated damage is occurring within host tissues is to measure end products of free radical oxidative processes. For example, when ROS react with polyunsaturated fatty acids, lipid peroxidation occurs. Peroxidation of lipids within cellular membranes can lead to changes in fluidity and cause damage to intracellular organelles. The determination of lipid hydroperoxide concentrations in plasma would be an indication of early stages of this lipid peroxidation damage. Measurements of lipid hydroperoxides in this study indicated an increase $(P$ $<0.05$ ) from calving through the first 3 wk of lactation when compared with the prepartum measurements (Figure 2). These findings are consistent with other reports in periparturient cows in which biomarkers of lipid peroxidation were found to increase from calving and through 25 DIM (Bernabucci et al., 2005; Castillo et al., 2005). These findings suggest that the reduced total antioxidant potential observed in PBMC obtained from transition cows during the first $3 \mathrm{wk}$ of lactation is more likely due to depleted antioxidant defense mechanisms, which are needed to reduce accumulated concentrations of ROS. The data from this study support the contentions of others that depletion of critical antioxidant defenses may predispose transition cows to ROS-induced pathologies during early lactation (Miller et al., 1993; Drackley, 1999). 
Table 2. Changes in the amount ${ }^{1}$ and ratio of reduced (GSH) and oxidized (GSSG) forms of glutathione in peripheral blood mononuclear cells obtained in the pre- and postcalving periods

\begin{tabular}{lccc}
\hline & \multicolumn{3}{c}{ Lactation stage $^{2}$} \\
\cline { 2 - 4 } Parameter & $\mathrm{C}-20$ & $\mathrm{C}-0$ & $\mathrm{C}+21$ \\
\hline GSH, $\mu M$ & $532.7 \pm 28.5^{\mathrm{a}}$ & $488.4 \pm 48.3^{\mathrm{a}}$ & $341.5 \pm 19.5^{\mathrm{b}}$ \\
GSSG, $\mu M$ & $1.3 \pm 0.3^{\mathrm{b}}$ & $3.6 \pm 0.7^{\mathrm{a}}$ & $0.8 \pm 0.1^{\mathrm{b}}$ \\
GSH:GSSG ratio & $546.9 \pm 97.7^{\mathrm{a}}$ & $171.1 \pm 25.8^{\mathrm{b}}$ & $575.3 \pm 114.3^{\mathrm{a}}$ \\
\hline
\end{tabular}

${ }^{\mathrm{a}, \mathrm{b}}$ Means among lactational stage differ $(P<0.05)$.

${ }^{1}$ Data are expressed as least squares means $\pm \mathrm{SE}$.

${ }^{2}$ Samples were obtained approximately $21 \mathrm{~d}$ before calving $(\mathrm{C}-21)$, at calving $(\mathrm{C}-0)$, and $21 \mathrm{~d}$ after calving $(\mathrm{C}+21)$.

Antioxidant defenses consist of a diverse group of molecules that are either produced endogenously or derived from the diet. The various antioxidant defense mechanisms also can be classified on the basis of several criteria, such as on their solubility in lipids and water or on their chemical and physical characteristics (i.e., enzymatic or nonenzymatic; Papas, 1999). An important thiol-containing compound that is often used to assess the antioxidant capacity of cells is GSH because it is the major nonenzymatic regulator of intracellular redox homeostasis. This Cys-containing tripeptide can exist in either a reduced form (GSH) or an oxidized form (GSSG). Under normal cellular redox conditions, the major portion of this redox regulator will be in the form of GSH. However, GSSG concentrations will increase during oxidative stress. The reduced GSH can act as a substrate in enzymatic reactions with GPX and participate in redox reactions by the reversible oxidation of its active thiol. An interesting finding of this study was the reduction $(P<0.05)$ in whole blood cell GSH concentrations from the pre- to the postpartum period (Table 2). The GSH concentrations may have become depleted at calving and during the postpartum period from the reduction of ROS and lipid hydroperoxides, which increase during this same stage of lactation (Figure 2). A similar finding in the total GSH content of blood cells in dairy cows around parturition was reported previously (Stefanon et al., 2005). However, our findings contrast with those recently reported by Bernabucci et al. (2005) in which plasma and erythrocyte thiol concentrations reached peak concentrations $4 \mathrm{~d}$ before calving through 10 DIM. A likely explanation for these disparate findings may be that the reducing capacity of all sulfhydryl groups was assessed in the latter study, whereas the present study evaluated GSH specifically. The latter study (Bernabucci et al., 2005) also measured plasma and erythrocyte thiol concentrations, which are possibly different from whole blood cell values.

In contrast to the GSH concentrations, an increase ( $P$ $<0.05$ ) in GSSG concentrations was observed in whole blood cells at the time of calving when compared with the pre- and postpartum measurements. The dramatic increase in GSSG concentrations at calving was negatively correlated $(-0.87, P<0.001)$ with a decrease $(P$ $<0.05$ ) in the GSH-to-GSSG ratio (Table 2), which indicates a shift in the redox potential of whole blood cells. Surprisingly, GSSG concentrations decreased $(P<0.05)$ and the GSH-to-GSSG ratio rebounded postpartum even though the lipid hydroperoxide levels in plasma remained high and the total antioxidant potential of PBMC was decreased (Figures 1 and 2). The rebound in the GSH-to-GSSG ratio postpartum would suggest sufficient enzymatic reduction of these particular sulfhydryl groups during times when ROS may be accumulating in the blood compartment, possibly by certain selenoprotein-containing enzymes.

The selenoprotein enzymes, including GPX and TrxR, have SeCys residues incorporated into their active site. Previous studies have shown that supplementing dairy cattle with adequate levels of Se will correlate with enhanced GPX concentrations and optimized host defenses against disease (Gerloff, 1992; Hogan et al., 1993). Increases in GPX concentrations also have been noted in dairy cattle plasma and whole blood cells during times of physiological and metabolic stress, which has been suggested as a cytoprotective response resulting from ROS accumulation (Bernabucci et al., 2005; Stefanon et al., 2005). Consistent with these earlier reports, the mean GPX activity in PBMC increased $(P<0.05)$ at calving and during the first 21 DIM when compared with concentrations during the prepartum period in the present study (Figure 3). The increase in GPX activity at calving coincided with the rise in plasma lipid hydroperoxide concentrations during the same time period (Figure 2). The increased enzyme activity of this selenoprotein observed postpartum would account for the rebound in the GSH-to-GSSG ratio in whole blood cell populations as well because GSH and GPX are known redox couples. The GPX concentrations in this study, however, remained elevated from calving through the first 21 DIM and did not parallel the decline 


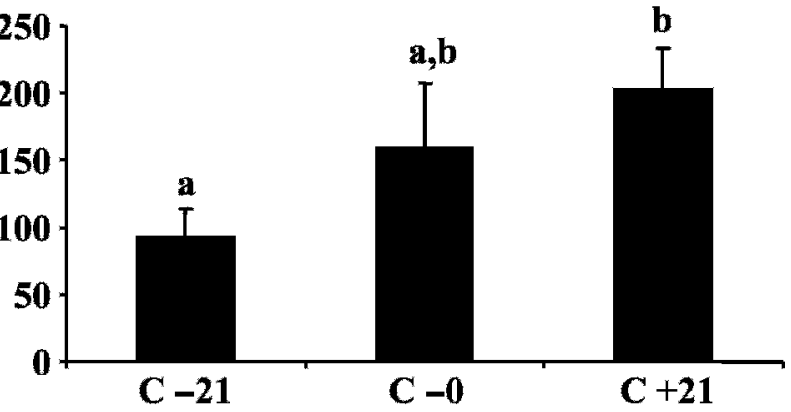

Figure 3. Changes in glutathione peroxidase (GPX1) activity in white blood cells obtained approximately $21 \mathrm{~d}$ before calving $(\mathrm{C}-21)$, at calving $(\mathrm{C}-0)$, and $21 \mathrm{~d}$ after calving $(\mathrm{C}+21)$. Data are expressed as least squares means $\pm \mathrm{SE}$. ${ }^{\mathrm{a}, \mathrm{b}}$ Bars bearing different letters differ $(P<0.05)$.

in the overall antioxidant potential of PBMC (Figure 1). Whereas plasma GPX concentrations are often measured to assess overall Se status and increases in ROS production in dairy cattle, the rise in GPX does not necessarily always correlate with oxidant stress or antioxidant potential in specific tissue compartments (Gromer et al., 2005). The fact that increased plasma lipid hydroperoxide concentrations (Figure 1) and diminished PBMC antioxidant potential (Figure 2) occur in the presence of elevated PBMC GPX activity, as reported in this study, would suggest that this antioxidant defense factor may not be the most efficient in controlling oxidative stress in immune cells in transition cows.

An antioxidant defense parameter that did change proportionately with measures of overall $\mathrm{PBMC}$ antioxidant potential was TrxR (Figure 4). To our knowledge, this is the first time that this antioxidant has been measured in transition dairy cattle. Like GPX, TrxR has the ability to directly reduce many different forms of hydroperoxides, including $\mathrm{H}_{2} \mathrm{O}_{2}$ and fatty acid hydroperoxides, to less reactive water and alcohols. The decline in TrxR activity (Figure 4) may be attributed to the accumulation of lipid hydroperoxides (Figure 2) and other ROS reported to occur through the early lactating period (Bernabucci et al., 2005). Plasma concentrations of TrxR are used as a marker of oxidative stress in a wide variety of human disorders (Nakamura, 2005), and the importance of TrxR as an essential protein in mammals is reflected by the fact that TrxR knockout mice are embryonic lethal (Matsui et al., 1996). The fact that TrxR concentrations in PBMC are depleted postpartum in dairy cattle when the antioxidant potential of these cells is also decreased may suggest that this

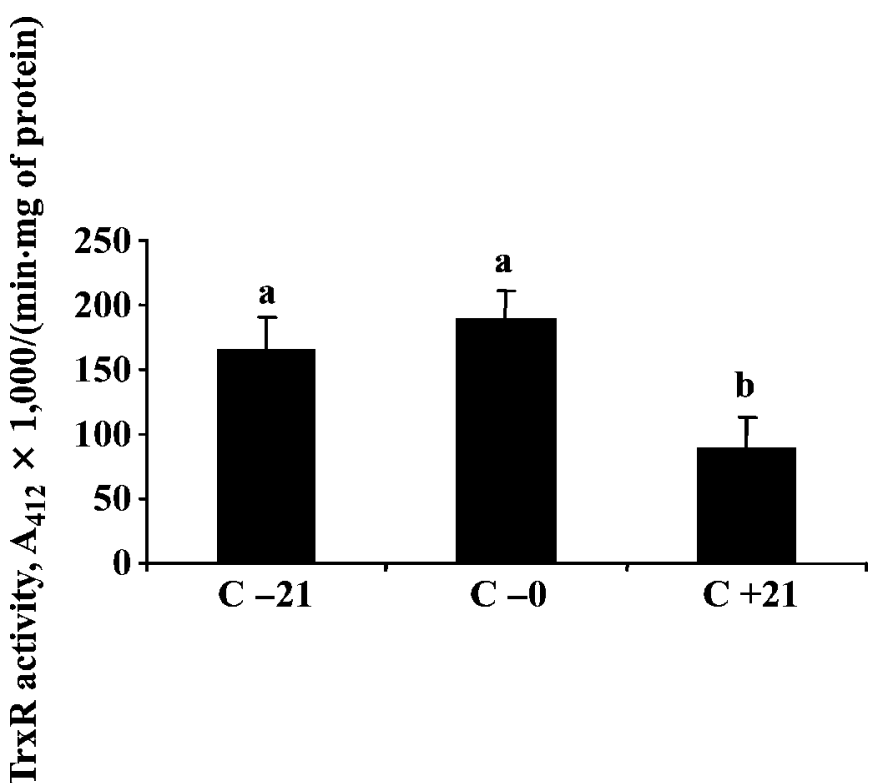

Figure 4. Changes in thioredoxin reductase (TrxR) activity in white blood cells obtained approximately $21 \mathrm{~d}$ before calving $(\mathrm{C}-21)$, at calving $(\mathrm{C}-0)$, and $21 \mathrm{~d}$ after calving $(\mathrm{C}+21)$. Data are expressed as least squares means $\pm \mathrm{SE}$. ${ }^{\mathrm{a}, \mathrm{b}}$ Bars bearing different letters differ $(P<0.05)$.

particular antioxidant is important to the antioxidant defense of PBMC during oxidant challenge. Previous studies have clearly shown that the PBMC functional capacity is diminished during the periparturient period (Sordillo, 2005). The possibility that enhancing the PBMC TrxR activity may alter the functional capabilities of immune cell populations during times of increased oxidant challenge is an intriguing hypothesis that arises from this descriptive study.

\section{CONCLUSIONS}

Transition cows experience oxidative stress during the early lactating period. The observed accumulation of lipid hydroperoxides at calving and during the first 21 DIM corresponds to an increase in GPX activity of PBMC. This observation is consistent with previous reports and supports the contention that GPX is an indicator of increased ROS production within host tissues. It is the decline in TrxR activity of PBMC, however, that parallels the decreased antioxidant potential and continued elevations in lipid hydroperoxide concentrations during the first 21 DIM. Our study shows for the first time that TrxR may be an important antioxidant defense mechanism in PBMC that is compromised during the periparturient period. Based on the initial descriptive data presented here, further studies are needed to establish the potential role of TrxR on the 
antioxidant capabilities of PBMC obtained from transition cows and to show how altered concentrations of this selenoprotein may influence the functional capabilities of immune cell populations during times of increased oxidative stress.

\section{ACKNOWLEDGMENTS}

This work was supported in part by a grant from the National Research Initiative of the USDA Cooperative State Research, Education and Extension Service, grant \#2005-01681, and by an endowment from the Matilda R. Wilson Fund (Detroit, MI). The authors acknowledge the technical contributions of Alica Gour, Candice Gandy, and Andres Contreras Bravo.

\section{REFERENCES}

Bernabucci, U., B. Ronchi, N. Lacetera, and A. Nardone. 2005. Influence of body condition score on relationships between metabolic status and oxidative stress in periparturient dairy cows. J. Dairy Sci. 88:2017-2026.

Bligh, E. G., and W. J. Dyer. 1959. A rapid method for total lipid extraction and purification. Can. J. Biochem. Physiol. 37:911-917.

Castillo, C., J. Hernandez, A. Bravo, M. Lopez-Alonso, V. Pereira, and J. L. Benedito. 2005. Oxidative status during late pregnancy and early lactation in dairy cows. Vet. J. 169:286-292.

Drackley, J. K. 1999. Biology of dairy cows during the transition period: The final frontier. J. Dairy Sci. 82:2259-2273.

Erskine, R. J., R. J. Eberhart, P. J. Grasso, and R. W. Scholz. 1989. Induction of Escherichia coli mastitis in cows fed selenium-deficient or selenium-supplemented diets. Am. J. Vet. Res. 50:2093-2100.

Erskine, R. J., R. J. Eberhart, L. J. Hutchinson, and R. W. Scholz. 1987. Blood selenium concentrations and glutathione peroxidase activities in dairy herds with high and low somatic cell counts. J. Am. Vet. Med. Assoc. 190:1417-1421.

Gerloff, B. J. 1992. Effect of selenium supplementation on dairy cattle. J. Anim. Sci. 70:3934-3940.

Gitto, E., R. J. Reiter, M. Karbownik, D. X. Tan, P. Gitto, S. Barberi, and I. Barberi. 2002. Causes of oxidative stress in the pre- and perinatal period. Biol. Neonate 81:146-157.

Grasso, P. J., R. W. Scholz, R. J. Erskine, and R. J. Eberhart. 1990. Phagocytosis, bactericidal activity, and oxidative metabolism of milk neutrophils from dairy cows fed selenium-supplemented and selenium-deficient diets. Am. J. Vet. Res. 51:269-274.

Grignard, E., J. Morin, P. Vernet, and J. R. Drevet. 2005. GPX5 orthologs of the mouse epididymis-restricted and sperm-bound selenium-independent glutathione peroxidase are not expressed with the same quantitative and spatial characteristics in large domestic animals. Theriogenology 64:1016-1033.
Gromer, S., J. K. Eubel, B. L. Lee, and J. Jacob. 2005. Human selenoproteins at a glance. Cell. Mol. Life Sci. 62:2414-2437.

Hara, S. 2001. Effects of selenium deficiency on expression of selenoproteins in bovine arterial endothelial cells. Biol. Pharm. Bull. 24:754-759.

Hill, K. E., G. W. McCollum, M. E. Boeglin, and R. F. Burk. 1997. Thioredoxin reductase activity is decreased by selenium deficiency. Biochem. Biophys. Res. Commun. 234:293-295.

Hogan, J. S., W. P. Weiss, and K. L. Smith. 1993. Role of vitamin $\mathrm{E}$ and selenium in host defense against mastitis. J. Dairy Sci. 76:2795-2803.

Holmgren, A., and M. Björnstedt. 1995. Thioredoxin and thioredoxin reductase. Meth. Enzymol. 252:199-208.

Matés, J. M., and F. Sánchez-Jiménez. 1999. Antioxidant enzymes and their implications in pathophysiologic processes. Front. Biosci. 4:D339-D345.

Matsui, M., M. Oshima, H. Oshima, K. Takaku, T. Maruyama, J. Yodoi, and M. M. Taketo. 1996. Early embryonic lethality caused by targeted disruption of the mouse thioredoxin gene. Dev. Biol. 178:179-185.

Miller, J. K., E. Brzezinska-Slebodzinska, and F. C. Madsen. 1993. Oxidative stress, antioxidants, and animal function. J. Dairy Sci. $76: 2812-2823$.

Nakamura, H. 2005. Thioredoxin and its related molecules: Update 2005. Antioxidants Redox Signaling 7:823-828.

Papas, A. M. 1999. Diet and antioxidant status. Food Chem. Toxicol. 37:999-1007.

Schomburg, L., U. Schweizer, and J. Kohrle. 2004. Selenium and selenoproteins in mammals: Extraordinary, essential, enigmatic. Cell. Mol. Life Sci. 61:1988-1995.

Smith, K. L., J. H. Harrison, D. D. Hancock, D. A. Todhunter, and H. R. Conrad. 1984. Effect of vitamin E and selenium supplementation on incidence of clinical mastitis and duration of clinical symptoms. J. Dairy Sci. 67:1293-1300.

Sordillo, L. M. 2005. Factors affecting mammary gland immunity and mastitis susceptibility. Livestock Prod. Sci. 98:89-99.

Sordillo, L. M., H. Soohoo, K. M. Aherne, C. C. Reddy, and J. S. Hogan. 1998. A method to reduce glutathione peroxidase levels in primary endothlial cell cultures. Meth. Cell Sci. 19:243-253.

Stefanon, B., S. Sgorlon, and G. Gabai. 2005. Usefulness of nutraceutics in controlling oxidative stress in dairy cows around parturition. Vet. Res. Commun. 29(Suppl. 2):387-390.

Trigona, W. L., I. K. Mullarky, Y. Cao, and L. M. Sordillo. 2006. Thioredoxin reductase regulates the induction of haem oxygenase-1 expression in aortic endothelial cells. Biochem. J. 394:207-216.

Waller, K. P. 2000. Mammary gland immunology around parturition. Influence of stress, nutrition and genetics. Adv. Exp. Med. Biol. 480:231-245.

Weiss, W. P., and J. S. Hogan. 2005. Effect of selenium source on selenium status, neutrophil function, and response to intramammary endotoxin challenge of dairy cows. J. Dairy Sci. 88:43664374 .

Wichtel, J. J. 1998. A review of selenium deficiency in grazing ruminants. Part 1: New roles for selenium in ruminant metabolism. N. Z. Vet. J. 46:47-52. 